\title{
Cytoprotective Effects of Glycine and Glutathione against Hypoxic Injury to Renal Tubules
}

\author{
Joel M. Weinberg, Julie A. Davis, Magaly Abarzua, and Thankamoni Rajan \\ Division of Nephrology, Department of Internal Medicine, Veterans Administration Medical Center, \\ and University of Michigan, Ann Arbor, Michigan 48109
}

\begin{abstract}
Roles for both the tripeptide, GSH, and individual amino acids in modifying the cellular response to oxygen deprivation-induced injury have been suggested by prior work in kidney and other tissues, but the precise interrelationships have not been clearly defined. We have studied the effects of GSH, its component amino acids, and related compounds on the behavior of isolated renal proximal tubules in a well characterized model of hypoxic injury in vitro. GSH, the combination of cysteine, glutamate, and glycine and glycine alone, when present in the medium during $\mathbf{3 0}$ min hypoxia, a duration sufficient to produce extensive irreversible injury in untreated tubules, were protective. Significant effects were detected at $0.25 \mathrm{mM}$ concentrations of the reagents, and protection was nearly complete at concentrations of $1 \mathrm{mM}$ and above. Glutamate and cysteine alone were not protective. The exogenous GSH added to the tubule suspensions was rapidly degraded to its component amino acids. Treatment of tubules with GSH or cysteine, but not glycine, increased intracellular GSH levels. Oxidized GSH was protective. Serine, $N$-(2-mercaptopropionyl)-glycine, and a panel of agents known to modify injury produced by reactive oxygen metabolites were without benefit. These observations identify a novel and potent action of glycine to modify the course of hypoxic renal tubular cell injury. This effect is independent of changes in cellular GSH metabolism and appears to be unrelated to alterations of cell thiols or reactive oxygen metabolites. Further elucidation of its mechanism may provide insight into both the basic pathophysiology of oxygen deprivation-induced cell injury and a practical way to ameliorate it.
\end{abstract}

\section{Introduction}

A number of processes have been implicated in the pathogenesis of oxygen deprivation-induced cell injury. These include disturbances of cell calcium metabolism, disruption of the cytoskeleton, depletion of cell adenine nucleotides, generation of free radicals, activation of phospholipases with production of toxic lipid metabolites, and loss of cell volume and monovalent cation homeostasis $(1,2)$. Complete delineation of the

Some of these data was published in abstract form (1987. Fed. Proc. 43:1330) (1987. Clin. Res. 33:559).

Address all correspondence to Dr. J. M. Weinberg, Nephrology Division, 3914 Taubman Health Care Center, University of Michigan Medical Center, Ann Arbor, MI 48109-0364.

Received for publication 31 March 1987 and in revised form 22 June 1987.

\section{J. Clin. Invest.}

(c) The American Society for Clinical Investigation, Inc. 0021-9738/87/11/1446/09 \$2.00

Volume 80, November 1987, 1446-1454 precise sequence of events has not been achieved for any tissue and is particularly complex in cell types such as the proximal renal tubular epithelium, where events occur relatively rapidly because of the dependence of these cells on high rates of oxidative metabolism. Recent studies have described the utility of isolated suspensions enriched in proximal tubules for studying the pathogenesis of oxygen deprivation-induced injury directly at the tubule cell level under highly controlled conditions in vitro and have identified substantial modulating effects on this process resulting from reduction of medium $\mathrm{pH}$ and treatment with high levels of exogenous nucleotides (3-5). GSH plays an important role in protecting cells from injury produced by a variety of reactive metabolites (6-8) and has been suggested to be involved in the cellular response to oxygen deprivation and reoxygenation $(9,10)$. Since this tripeptide is extensively metabolized by the kidney (11-13), any analysis of its effects on the cellular response to injury must also include an assessment of its component amino acids, particularly in view of data indicating that amino acids influence the development of tubule cell injury (14-18). In this paper we describe striking protective effects of GSH on the development of hypoxic proximal tubule cell injury, which appear to be largely explained by a previously unsuspected cytoprotective effect of its component amino acid, glycine. This information provides a new, highly effective means of modulating the course of oxygen deprivation-induced renal tubule cell injury and probing its pathogenesis.

\section{Methods}

Animals. Female New Zealand White rabbits (Shankin's Rabbitry, Warren, MI) weighing an average of $2.5 \mathrm{~kg}$ were used for these studies.

Tubule isolation. The procedure was similar to that employed in recent publications from this laboratory to prepare suspensions enriched in proximal tubules $(3,4)$. Rabbits were anesthetized by injection of $25 \mathrm{mg} / \mathrm{kg}$ sodium thiamylal into an ear vein. The abdominal cavity was opened, both kidneys were rapidly removed and were immediately placed into an ice-cold solution containing $115 \mathrm{mM} \mathrm{NaCl}$, $2.1 \mathrm{mM} \mathrm{KCl}, 25 \mathrm{mM} \mathrm{NaHCO}_{3}, 2.4 \mathrm{mM} \mathrm{KH}_{2} \mathrm{PO}_{4}, 1.2 \mathrm{mM} \mathrm{CaCl}_{2}, 1.2$ $\mathrm{mM} \mathrm{MgCl} 2$, and $1.2 \mathrm{mM} \mathrm{MgSO}_{4}$ previously gassed with and kept under $95 \% \mathrm{O}_{2} / 5 \% \mathrm{CO}_{2}(\mathrm{pH} 7.2)$ at $4^{\circ} \mathrm{C}$ (solution $\left.\mathrm{A}\right)$. The rabbit was then killed with an overdose of thiamylal. The renal cortices were dissected on an ice-cold tile and were minced with a razor blade. All tissue from one rabbit was then placed into a siliconized 250-ml Erlenmeyer flask containing $24 \mathrm{ml}$ of a solution with an electrolyte composition identical to solution $\mathrm{A}$ except that $\mathrm{CaCl}_{2}$ was increased to 2.4 $\mathrm{mM} ; \mathrm{KH}_{2} \mathrm{PO}_{4}$, decreased to $1.2 \mathrm{mM}$, and $\mathrm{KCl}$, increased to $3.3 \mathrm{mM}$. The higher $\mathrm{Ca}^{2+}$ was used to facilitate the action of collagenase. Also, the medium contained $25 \mathrm{mM}$ mannitol, $2.5 \mathrm{mg} / \mathrm{ml}$ fatty acid-free bovine serum albumin (BSA), $5 \mathrm{mM}$ glucose, $4 \mathrm{mM}$ sodium lactate, 1 $\mathrm{mM}$ alanine, $1 \mathrm{mM}$ sodium butyrate, and $24 \mathrm{mg}$ of collagenase (type I; CooperBiomedical, Inc., Malvern, PA). The flask was gassed with $95 \%$ $\mathrm{O}_{2} / 5 \% \mathrm{CO}_{2}$, sealed, and placed in a shaking water bath at $37^{\circ} \mathrm{C}$. The flask was then gently shaken for $30-40 \mathrm{~min}$, depending on the activity of the particular lot of collagenase being used. 
At the end of the collagenase treatment period, the flask was removed from the water bath, opened, and $75 \mathrm{ml}$ of ice-cold solution A were added. The suspension was then filtered through a strainer to remove any remaining pieces of tissue. The filtrate was then centrifuged in two $50-\mathrm{ml}$ tubes in a refrigerated centrifuge at $4^{\circ} \mathrm{C}$ for $2 \mathrm{~min}$ at $30 \mathrm{~g}$ to separate a pellet of intact tubules and glomeruli from subcellular debris that remain largely in the supernatant. The tubule pellet was gently resuspended in solution $\mathrm{A}$ and recentrifuged. This pellet was then resuspended in $10 \mathrm{ml}$ of fresh solution A containing 5\% BSA and was centrifuged again. The resulting pellet was resuspended in $35 \mathrm{ml}$ of solution identical in electrolyte composition to solution $\mathrm{A}$ and containing 48\% Percoll (Pharmacia Fine Chemicals, Piscataway, NJ). This suspension was centrifuged for $30 \mathrm{~min}$ at $37,000 \mathrm{~g}$ (RC-2; Sorvall Instruments Div. [part of DuPont Co.], Newton, CT). The resulting gradient effectively separates lighter glomeruli and distal tubule segments from more dense proximal tubule segments. The layer enriched in proximal tubule segments was taken from the gradient with a Pasteur pipette and washed twice with solution A to remove the Percoll, yielding mostly short lengths of proximal tubules.

Basic procedures for study of the final tubule preparation. The final tubule pellet was resuspended to a concentration of 5-7.5 mg tubule protein $/ \mathrm{ml}$ in a $95 \% \mathrm{O}_{2} / 5 \% \mathrm{CO}_{2}$ gassed ice-cold solution of the same electrolyte composition as solution $\mathrm{A}$ with the addition of $0.6 \%$ dialyzed dextran (T40; Pharmacia Fine Chemicals), $5 \mathrm{mM}$ glucose, $1 \mathrm{mM}$ alanine, $4 \mathrm{mM}$ sodium lactate, and $10 \mathrm{mM}$ sodium butyrate. Total $\mathrm{Na}^{+}$was kept constant by reducing $\mathrm{NaCl}$ to account for $\mathrm{Na}^{+}$added with the substrates. $5.0 \mathrm{ml}$ aliquots of this tubule suspension were placed in siliconized 25-ml Erlenmeyer flasks that were then gassed with $95 \% \mathrm{O}_{2} / 5 \% \mathrm{CO}_{2}$, sealed, and kept on ice until use. As they were needed for experiments, flasks were placed in a shaking water bath at $37^{\circ} \mathrm{C}$ and were gently shaken for the desired periods of warm incubation. For most oxygen deprivation studies, tubules were initially incubated at $37^{\circ} \mathrm{C}$ for $15 \mathrm{~min}$. Then flasks were gassed for $5 \mathrm{~min}$ with $95 \%$ $\mathrm{N}_{2} / 5 \% \mathrm{CO}_{2}$, sealed, and returned to the metabolic shaker for the 30 min period of hypoxia. At the end of this interval tubules were either sampled for measurement of metabolites or were regassed for 2 min with $95 \% \mathrm{O}_{2} / 5 \% \mathrm{CO}_{2}$, sealed, and returned to the metabolic shaker for 60 min of continued incubation under oxygenated conditions.

Measurement of tubule respiration. A sample of tubule suspension was used to fill a $1.9-\mathrm{ml}$ sealed, temperature controlled $\left(37^{\circ} \mathrm{C}\right)$ chamber equipped with a magnetic stirrer and a Clark oxygen electrode (Gilson Medical Electronics, Inc., Middleton, WI), and oxygen consumption was measured under basal conditions followed by addition of the mitochondrial uncoupler, carbonyl cyanide $m$-chlorophenylhydrazone (CCCLP) ${ }^{1}(15 \mu \mathrm{M})$. Rates of oxygen consumption were factored for total suspension protein.

Measurement of tubule $\mathrm{K}^{+}$content and protein recovery. For measurement of cell $\mathrm{K}^{+}$levels, tubules were rapidly separated from their suspending medium by gently layering $0.5 \mathrm{ml}$ of tubule suspension into a $1.5-\mathrm{ml}$ microcentrifuge tube containing $0.7 \mathrm{ml}$ bromododecane (Aldrich Chemical Co., Milwaukee, WI) that had previously been layered on $0.2 \mathrm{ml}$ of $275 \mathrm{mM}$ sucrose containing 4\% Ficoll (Pharmacia Fine Chemicals) to increase its density while maintaining isotonicity. The tube was then centrifuged in a microcentrifuge at maximal speed $(12,000 \mathrm{~g})$ for $30 \mathrm{~s}$ to pellet the tubules in the bottom sucrose layer. The supernatant remains above the bromododecane layer and was then removed as was the bromododecane. $\mathrm{K}^{+}$levels of the tubules in the bottom sucrose-Ficoll layer were measured by atomic absorption spectroscopy (19) and were factored for pellet protein. Since the centrifugation procedure favors passage of the more intact tubules through bromododecane into the sucrose-Ficoll, the percent of total suspension protein recovered in this fashion was calculated as another index of tubule cell integrity $(3,4)$.

1. Abbreviations used in this paper: CCCLP, carbonyl cyanide mchlorophenyl-hydrazone; CGG, $2 \mathrm{mM}$ cysteine plus $2 \mathrm{mM}$ glutamate plus $2 \mathrm{mM}$ glycine; CoA, coenzyme $\mathrm{A}$.
Measurement of ATP levels. To measure total suspension ATP levels, $0.4 \mathrm{ml}$ of tubule suspension was added to an equal volume of $12 \%$ trichloroacetic acid in a $1.5-\mathrm{ml}$ microcentrifuge tube that was vigorously mixed and then centrifuged. The supernatant was removed from the protein pellet and was neutralized and extracted by mixing with an equal volume of $0.5 \mathrm{M}$ tri-n-octylamine (Aldrich Chemical Co.) in Freon-113 (Matheson Gas Products, Inc., Seacaucus, NJ). Separation of the freon and aqueous layers was facilitated by a brief centrifugation. Then the aqueous layer was removed, filtered through 0.45 -micron nitrocellulose filters, and frozen.

ATP was quantified on $20 \mu$ l aliquots of sample by high performance liquid chromatography (HPLC) at an absorbance of $254 \mathrm{~nm}$ with a $\mathrm{C}_{18}$ ion pairing reversed phase column (Beckman Instruments, Inc., Fullerton, $\mathrm{CA}$ ) using an isocratic mobile phase consisting of $19 \%$ acetonitrile, $40 \mathrm{mM} \mathrm{KH}_{2} \mathrm{PO}_{4}$, and $10 \mathrm{mM}$ tetrabutylammonium dihydrogen phosphate, $\mathrm{pH} 3.5$ at $24^{\circ} \mathrm{C}$, and a flow rate of $1 \mathrm{ml} / \mathrm{min}$. Suspension ATP levels were factored for total suspension protein.

HPLC amino acid analysis. Samples of tubule suspending medium obtained after removal of tubules by centrifugation were derivatized using a coupling buffer consisting of ethanol/triethanolamine/water/ phenylisothiocyanate $(7: 1: 1: 1)$ by incubation for $20 \mathrm{~min}$ at room temperature. They were then vacuum dried for $5 \mathrm{~min}$ and dissolved in 50 $\mathrm{mM}$ potassium phosphate, $\mathrm{pH} 7.0,15 \%$ acetonitrile (20). HPLC analysis of individual amino acids was done using a Nova-Pak $C_{18}$ column (Waters Associates, Millipore Corp., Milford, MA), as detailed in reference 20.

Measurement of cellular GSH levels. Tubules were separated from their medium by centrifugation through bromododecane into $12 \%$ trichloroacetic acid that was then extracted and neutralized with tri- $n$ octylamide-freon as described for measurement of cell ATP levels. GSH was determined fluorometrically in a medium consisting of 100 $\mathrm{mM}$ sodium phosphate, $5 \mathrm{mM}$ EDTA, $\mathrm{pH} 8.0$, plus $50 \mu \mathrm{g} / \mathrm{ml} \sigma$ phthaldialdehyde at an excitation wavelength of $350 \mathrm{~nm}$ and an emission wavelength of $420 \mathrm{~nm}$ (21).

Protein assay. Proteins were quantified by the Lowry assay with BSA as the standard (22).

Reagents. All reagents were of the highest grade commercially available. Biochemical reagents were obtained from Sigma Chemical Co. (St. Louis, MO) unless otherwise indicated. $L$-amino acids were used for all studies.

Statistics. Most experiments involved repeated measures and were, therefore, assessed by paired $t$ tests or analysis of variance using models accounting for repeated measure designs (BMDP Statistical Software, Los Angeles, CA) (23). Individual group comparisons in the multigroup studies were then made using the Neuman-Keuls test for multiple comparisons (24).

\section{Results}

Several parameters have been found to be useful for quantitating the metabolic and structural integrity of the isolated tubule preparation. These include tubule respiratory rates, ATP levels, total cell $\mathrm{K}^{+}$levels, and the extent of recovery of tubule protein after centrifugation through bromododecane $(3,4)$. Figs. 1 and 2 and Table I summarize the effects of treatment with either $2 \mathrm{mM}$ GSH or each of its component amino acids individually and in combination ( $2 \mathrm{mM}$ cysteine plus $2 \mathrm{mM}$ glutamate plus $2 \mathrm{mM}$ glycine [CGG]) on the behavior of these parameters in tubules subjected to $30 \mathrm{~min}$ hypoxia followed by $60 \mathrm{~min}$ reoxygenation. $30 \mathrm{~min}$ hypoxia has previously been shown to produce extensive oxygen deprivation-induced tubule injury in the preparation $(3,4)$.

GSH, the combination of all three of its component amino acids (CGG group), and glycine alone, but not cysteine or glutamate, substantially improved both basal and uncoupled respiratory rates of the tubules to levels approaching those of 


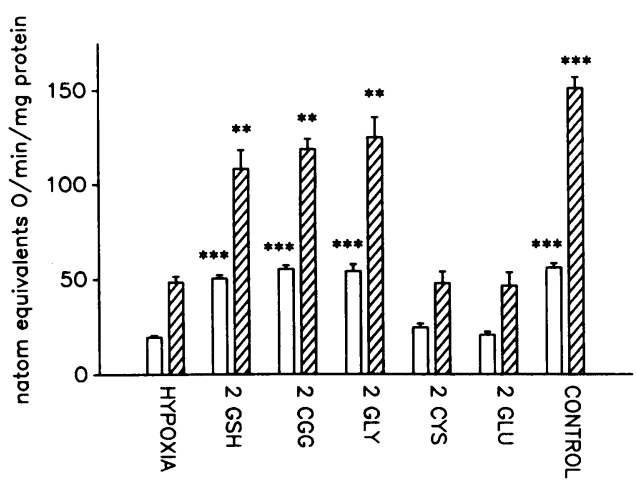

Figure 1. Tubule respiratory rates (RR) following $15 \mathrm{~min}$ preincubation, $30 \mathrm{~min}$ hypoxia, and $60 \mathrm{~min}$ reoxygenation. The indicated agents were present throughout. 2 GSH, 2 mM GSH; 2 CGG, 2 mM CGG; 2 GLY, 2 mM glycine; 2 CYS, 2 mM cysteine; 2 glu, 2 mM glutamate; HYPOXIA, no addition; CONTROL, no addition; oxygenated throughout. Values are means \pm SE for five to seven experiments. $* * P<0.01$ and $* * * P<0.001$ vs. paired untreated hypoxia tubules. (ㅁ) Basal RR; (四) CCCLP RR.

control tubules not subjected to hypoxia (Figs. 1 and 2). That this respiration was coupled to both ATP production and to utilization of ATP for maintenance of cell monovalent cation homeostasis is indicated by the similar degrees of improvement produced by GSH, CGG, or glycine in cell ATP and $\mathrm{K}^{+}$ levels (Table I). None of these parameters was improved by cysteine or glutamate.

Protein recovery after centrifugation through bromododecane was significantly reduced after hypoxia, but not to the same degree as the respiratory rates, ATP, and $\mathrm{K}^{+}$levels. GSH, CGG, and glycine all significantly improved protein recovery, maintaining it at the levels seen in controls. Cysteine and glutamate were without effect relative to untreated hypoxia tubules (Table I).

Fig. 2 and Table I also summarize the results of studies to determine the dose dependency of the actions of GSH and glycine. Significant effects of both compounds were detectable down to concentrations of $0.25 \mathrm{mM}$.

The behavior of metabolic parameters of oxygenated tubules exposed to GSH, CGG, glycine, or cysteine is summarized in Table II. Values are given for 15, 45, and $105 \mathrm{~min}$ of incubation. These durations correspond, respectively, to the initiation of hypoxia, the end of hypoxia, and the end of 60 min of reoxygenation in the oxygen-deprivation studies. Neither basal respiratory rates nor ATP nor $\mathrm{K}^{+}$levels were affected by any of the agents. CCCLP-uncoupled respiratory rates tended to be lower after GSH, CGG, and cysteine, but the differences relative to paired controls were significant only at 15 and 45 min of incubation with cysteine. These observations indicate that the improvements in respiratory rates, ATP, and $\mathrm{K}^{+}$levels seen in the hypoxic tubules were due to unique effects on the response to hypoxia rather than to generalized metabolic changes also seen in oxygenated tubules.

In the experiments described to this point, test agents were present from the beginning of tubule incubation at $15 \mathrm{~min}$ before the start of hypoxia and then throughout hypoxia and recovery. To better define the timing of the protective effects, studies were done in which GSH or glycine was present for an

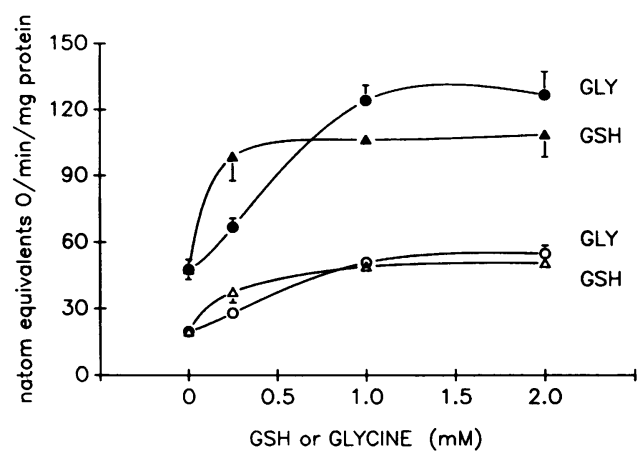

Figure 2. Dose dependence of effects of glycine and GSH on tubule cell respiration following hypoxia. Tubules were preincubated for 15 min with the indicated concentration of GSH (triangles) or glycine (circles) then were subjected to $30 \mathrm{~min}$ hypoxia and $60 \mathrm{~min}$ reoxygenation followed by measurement of basal (open symbols) and CCCLP-uncoupled respiration (closed symbols). Values are means \pm SE for five to seven experiments. Both basal and uncoupled rates were significantly $(P<0.05$ or better) greater than paired controls in all treated groups. Absent standard error bars were smaller than symbols for those points.

initial 30 min of preincubation, but tubules were washed ${ }^{2}$ just before starting hypoxia or the compounds were added at the start of hypoxia or at the end of hypoxia when tubules were reoxygenated. Removing GSH or glycine by a single wash before hypoxia completely eliminated their protective effects and no protection was observed when they were added at the end of hypoxia (Table III). A high degree of protection was seen when GSH or glycine was added at the beginning of hypoxia without a period of preincubation (Table III). Thus, GSH and glycine must be present at effective concentrations in the medium during hypoxia for their protective effects to be exerted. Neither changes in cell metabolism induced by preincubation nor effects during reoxygenation contribute to the protection.

Since most protection occurred during hypoxia, tubule metabolic parameters were measured in cells at the end of hypoxia, before reoxygenation (Table I). Cell $\mathrm{K}^{+}$levels were just as low in GSH- and glycine-treated tubules as in untreated tubules. Cell ATP levels of GSH-treated tubules were the same as those of untreated tubules; however, ATP levels of glycinetreated tubules were slightly, but significantly greater than those of untreated tubules. The decrement of tubule protein recovery occurred entirely during hypoxia in untreated tubules. The protective effects of GSH and glycine on this parameter were fully evident at the end of hypoxia.

Table IV summarizes the results of studies with several compounds related to GSH and glycine and with other agents known to modify cell injury caused by reactive oxygen metabolites. GSSG, the oxidized form of GSH, was protective. Ser-

2. For washing, the suspension from a single flask was transferred to a $15-\mathrm{ml}$ tube in a table top centrifuge that was turned on for $15 \mathrm{~s}$. This pelleted all the tubules to a degree that allowed them to be resuspended by gently inverting the tube, thus avoiding any mixing trauma. Tubules were washed in this fashion once using oxygenated medium containing all substrates, but without glycine or GSH. Then they were resuspended in a third aliquot of fresh medium. This entire procedure took 2-3 min and did not damage the tubules. Immediately after it was completed tubules were gassed with $95 \% \mathrm{~N}_{2} / 5 \% \mathrm{CO}_{2}$ to initiate hypoxia. 
Table I. Metabolic Parameters of Tubules at the End of 30 min Hypoxia and 30 min Hypoxia Plus 60 min Reoxygenation

\begin{tabular}{|c|c|c|c|c|c|c|}
\hline & \multicolumn{2}{|l|}{30 min hypoxia } & \multirow[b]{2}{*}{ Protein recovery } & \multicolumn{2}{|c|}{$\begin{array}{l}30 \text { min hypoxia plus } 60 \mathrm{~min} \\
\text { reoxygenation }\end{array}$} & \multirow[b]{2}{*}{ Protein recovery } \\
\hline & ATP & $\mathrm{K}^{+}$ & & ATP & $\mathrm{K}^{+}$ & \\
\hline & \multicolumn{2}{|l|}{ nmol/mg protein } & $\%$ & \multicolumn{2}{|l|}{ nmol/mg protein } & $\%$ \\
\hline Hypoxic tubules & $0.51 \pm 0.05$ & $75.0 \pm 3.1$ & $58.2 \pm 2.7$ & $2.34 \pm 0.18$ & $201.8 \pm 7.7$ & $66.9 \pm 2.2$ \\
\hline Control tubules & $8.12 \pm 0.47^{*}$ & $347.6 \pm 6.4^{*}$ & $101.5 \pm 2.1^{*}$ & $9.19 \pm 0.28^{*}$ & $354.3 \pm 8.5^{*}$ & $98.3 \pm 1.8^{*}$ \\
\hline \multicolumn{7}{|l|}{ Glycine $(m M)$} \\
\hline 0.25 & $0.49 \pm 0.08$ & $70.4 \pm 5.1$ & $65.0 \pm 3.5$ & $3.31 \pm 0.21^{\ddagger}$ & $237.8 \pm 13.9$ & $82.2 \pm 1.6^{\S}$ \\
\hline 1.0 & $1.01 \pm 0.11$ & $74.7 \pm 4.1$ & $93.6 \pm 5.7^{\ddagger}$ & $6.38 \pm 0.05^{*}$ & $317.7 \pm 16.2^{\ddagger}$ & $92.8 \pm 3.7^{\S}$ \\
\hline 2.0 & $0.94 \pm 0.08^{\S}$ & $80.1 \pm 4.8$ & $88.1 \pm 4.3^{\S}$ & $6.93 \pm 0.57^{*}$ & $352.3 \pm 15.3^{\ddagger}$ & $95.9 \pm 4.8^{\ddagger}$ \\
\hline \multicolumn{7}{|l|}{ GSH $(m M)$} \\
\hline 0.25 & $0.48 \pm 0.08$ & $79.8 \pm 6.1$ & $68.5 \pm 3.5$ & $5.07 \pm 0.69^{\S}$ & $291.6 \pm 28.8^{\S}$ & $79.7 \pm 4.3$ \\
\hline 1.0 & $0.72 \pm 0.20$ & $75.3 \pm 3.7$ & $90.1 \pm 7.3^{\S}$ & $7.34 \pm 0.32^{*}$ & $329.0 \pm 21.4^{*}$ & $88.4 \pm 3.7^{\S}$ \\
\hline 2.0 & $0.64 \pm 0.06$ & $78.1 \pm 2.5$ & $87.7 \pm 3.8$ & $6.32 \pm 0.39^{*}$ & $346.4 \pm 6.5^{\ddagger}$ & $93.3 \pm 3.3^{\S}$ \\
\hline $2.0 \mathrm{mM}$ CGG & $0.97 \pm 0.16$ & $84.1 \pm 5.6$ & $88.6 \pm 3.3^{\ddagger}$ & $7.84 \pm 0.41^{*}$ & $340.3 \pm 15.5^{\ddagger}$ & $89.9 \pm 4.2^{\S}$ \\
\hline $2.0 \mathrm{mM}$ cysteine & - & - & - & $3.00 \pm 0.28$ & $218.5 \pm 8.7$ & $73.3 \pm 4.6$ \\
\hline $2.0 \mathrm{mM}$ glutamate & - & - & - & $2.85 \pm 0.26$ & $233.6 \pm 13.7$ & $71.6 \pm 3.6$ \\
\hline
\end{tabular}

Experimental reagents were present at the indicated concentrations from the beginning of $37^{\circ} \mathrm{C}$ incubation, 15 min before starting hypoxia. Values are means \pm SE for five to seven experiments at each concentration. In studies summarized in this table and Tables III and IV, each experiment testing a particular reagent was paired with untreated hypoxia and control experiments done with the same tubule preparation. Statistical analysis was in comparison with the paired $30 \mathrm{~min}$ hypoxia and $30 \mathrm{~min}$ hypoxia plus reoxygenation tubules, ${ }^{*} P<0.001$, ${ }^{\ddagger} P<0.01,{ }^{\S} P<0.05$. For conciseness of presentation, data shown for untreated hypoxic and control tubules are means of values obtained from the paired experiments of all summarized study groups.

Table II. Effects of GSH and Its Component Amino Acids on Metabolic Parameters of Oxygenated Tubules

\begin{tabular}{|c|c|c|c|c|c|}
\hline & \multicolumn{2}{|l|}{ Respiration } & \multirow[b]{2}{*}{ ATP } & \multirow[b]{2}{*}{$\mathrm{K}^{+}$} & \multirow[b]{2}{*}{ Protein recovery } \\
\hline & Basal & CCCLP & & & \\
\hline & \multicolumn{2}{|c|}{ natom eq oxygen/min per mg protein } & nmol/mg protein & & $\%$ \\
\hline \multicolumn{6}{|l|}{15 min incubation } \\
\hline Control & $53.0 \pm 1.8$ & $142.2 \pm 3.9$ & $7.22 \pm 0.76$ & $315.5 \pm 8.9$ & $109.6 \pm 2.9$ \\
\hline $0.25 \mathrm{mM}$ GSH & $60.5 \pm 2.9$ & $149.3 \pm 12.0$ & $7.00 \pm 0.12$ & $317.3 \pm 10.0$ & $106.9 \pm 1.6$ \\
\hline $2.0 \mathrm{mM}$ GSH & $51.3 \pm 3.4$ & $120.6 \pm 9.4$ & $7.14 \pm 0.79$ & $333.0 \pm 6.4$ & $96.6 \pm 4.0$ \\
\hline $2.0 \mathrm{mM}$ CGG & $59.7 \pm 4.3$ & $127.5 \pm 8.8$ & $6.96 \pm 0.42$ & $315.8 \pm 9.6$ & $99.0 \pm 1.9$ \\
\hline $2.0 \mathrm{mM}$ glycine & $54.3 \pm 3.9$ & $151.3 \pm 10.8$ & $7.00 \pm 0.86$ & $302.0 \pm 8.0$ & $100.8 \pm 2.2$ \\
\hline $2.0 \mathrm{mM}$ cysteine & $57.1 \pm 3.2$ & $116.5 \pm 10.3^{*}$ & $6.52 \pm 0.48$ & $315.8 \pm 5.5$ & $100.0 \pm 3.2$ \\
\hline \multicolumn{6}{|l|}{45 min incubation } \\
\hline Control & $53.2 \pm 3.9$ & $149.9 \pm 13.7$ & $8.20 \pm 0.81$ & $304.9 \pm 14.6$ & $105.3 \pm 14.9$ \\
\hline $0.25 \mathrm{mM}$ GSH & $55.3 \pm 3.4$ & $147.7 \pm 11.3$ & $7.73 \pm 0.81$ & $307.5 \pm 7.8$ & $104.6 \pm 3.7$ \\
\hline $2.0 \mathrm{mM} \mathrm{GSH}$ & $60.6 \pm 5.9$ & $129.9 \pm 13.1$ & $8.32 \pm 0.71$ & $307.5 \pm 5.6$ & $101.6 \pm 2.8$ \\
\hline $2.0 \mathrm{mM}$ CGG & $59.3 \pm 6.1$ & $122.5 \pm 14.5$ & $7.68 \pm 1.17$ & $313.4 \pm 3.7$ & $97.4 \pm 2.5$ \\
\hline $2.0 \mathrm{mM}$ glycine & $51.8 \pm 3.2$ & $153.5 \pm 12.9$ & $8.47 \pm 0.70$ & $324.1 \pm 8.4$ & $96.4 \pm 3.3$ \\
\hline $2.0 \mathrm{mM}$ cysteine & $53.1 \pm 2.6$ & $113.2 \pm 12.1^{*}$ & $7.98 \pm 0.67$ & $303.8 \pm 8.7$ & $95.8 \pm 1.5$ \\
\hline \multicolumn{6}{|l|}{$105 \mathrm{~min}$ incubation } \\
\hline Control & $53.9 \pm 4.4$ & $127.4 \pm 12.5$ & $9.76 \pm 0.55$ & $321.7 \pm 9.7$ & $109.4 \pm 4.4$ \\
\hline $0.25 \mathrm{mM}$ GSH & $57.2 \pm 3.3$ & $152.7 \pm 14.6$ & $9.02 \pm 1.22$ & $339.1 \pm 6.7$ & $103.1 \pm 4.1$ \\
\hline $2.0 \mathrm{mM} \mathrm{GSH}$ & $57.9 \pm 2.8$ & $114.8 \pm 10.9$ & $9.36 \pm 0.72$ & $331.2 \pm 13.7$ & $93.3 \pm 2.3$ \\
\hline $2.0 \mathrm{mM} \mathrm{CGG}$ & $59.0 \pm 1.7$ & $96.4 \pm 5.1$ & $8.12 \pm 0.67$ & $333.3 \pm 15.8$ & $96.9 \pm 0.8$ \\
\hline $2.0 \mathrm{mM}$ glycine & $52.0 \pm 3.7$ & $139.6 \pm 7.0$ & $10.34 \pm 0.88$ & $336.4 \pm 16.6$ & $97.7 \pm 6.5$ \\
\hline $2.0 \mathrm{mM}$ cysteine & $52.6 \pm 2.2$ & $112.9 \pm 10.2$ & $8.14 \pm 0.90$ & $320.9 \pm 12.4$ & $93.2 \pm 4.7$ \\
\hline
\end{tabular}

* $P<0.05$ vs. corresponding control group. Tubules were incubated for either 15,45 , or 105 min with the indicated agents. Values are means $\pm \mathrm{SE}$ for five experiments. 
Table III. Timing Requirements for Glycine and GSH-induced Protection from Hypoxic Tubule Cell Injury

\begin{tabular}{|c|c|c|c|c|c|}
\hline & \multicolumn{2}{|l|}{ Respiration } & \multirow[b]{2}{*}{ ATP } & \multirow[b]{2}{*}{$\mathrm{K}^{+}$} & \multirow[b]{2}{*}{ Protein recovery } \\
\hline & Basal & CCCLP & & & \\
\hline & \multicolumn{2}{|c|}{ natom eq oxygen/min per $\mathrm{mg}$ protein } & $\mathrm{nmol} / \mathrm{mg}$ protein & & $\%$ \\
\hline Posthypoxic & $18.9 \pm 1.0$ & $47.9 \pm 2.6$ & $1.97 \pm 0.19$ & $196.3 \pm 7.5$ & $67.3 \pm 2.6$ \\
\hline Control & $56.5 \pm 1.4^{*}$ & $160.0 \pm 5.4^{*}$ & $8.89 \pm 0.40^{*}$ & $346.7 \pm 8.2^{*}$ & $98.6 \pm 1.6^{*}$ \\
\hline \multicolumn{6}{|c|}{ I. Addition at start of hypoxia } \\
\hline $5 \mathrm{mM}$ GSH & $54.2 \pm 1.2^{*}$ & $101.0 \pm 5.3^{\ddagger}$ & $7.48 \pm 0.43^{*}$ & $339.9 \pm 21.4^{\ddagger}$ & $90.2 \pm 2.8^{\S}$ \\
\hline $2 \mathrm{mM}$ glycine & $51.3 \pm 1.1^{*}$ & $136.2 \pm 7.6^{*}$ & $7.37 \pm 0.24^{*}$ & $326.8 \pm 11.0^{\ddagger}$ & $97.5 \pm 5.1^{\ddagger}$ \\
\hline $2 \mathrm{mM}$ CGG & $53.8 \pm 2.0^{*}$ & $112.7 \pm 4.7^{*}$ & $7.84 \pm 0.41^{*}$ & $337.4 \pm 13.9^{*}$ & $97.3 \pm 2.4^{*}$ \\
\hline \multicolumn{6}{|c|}{ II. Addition at end of hypoxia } \\
\hline $2 \mathrm{mM}$ GSH & $17.8 \pm 1.4$ & $40.6 \pm 4.4$ & $0.75 \pm 0.16$ & $194.2 \pm 6.9$ & $55.4 \pm 5.2$ \\
\hline $2 \mathrm{mM}$ glycine & $17.0 \pm 1.7$ & $44.2 \pm 6.3$ & $1.54 \pm 0.42$ & $201.9 \pm 15.4$ & $61.1 \pm 4.0$ \\
\hline $2 \mathrm{mM}$ cysteine & $24.9 \pm 2.2$ & $48.4 \pm 6.0$ & $1.49 \pm 0.42$ & $209.3 \pm 12.8$ & $53.3 \pm 3.7$ \\
\hline $2 \mathrm{mM}$ glutamate & $17.7 \pm 1.6$ & $42.3 \pm 7.2$ & $1.58 \pm 0.42$ & $204.2 \pm 23.9$ & $62.5 \pm 3.0$ \\
\hline \multicolumn{6}{|c|}{ III. 30 min incubation followed by washing before hypoxia } \\
\hline Untreated & $22.9 \pm 1.7$ & $63.2 \pm 5.5$ & $3.43 \pm 0.23$ & $253.3 \pm 11.2$ & $71.4 \pm 2.7$ \\
\hline $5 \mathrm{mM}$ GSH & $32.3 \pm 4.8$ & $54.8 \pm 8.3$ & $4.13 \pm 0.40$ & $271.4 \pm 13.0$ & $74.1 \pm 3.4$ \\
\hline $2 \mathrm{mM}$ glycine & $26.5 \pm 2.0$ & $62.8 \pm 4.7$ & $3.75 \pm 0.32$ & $289.8 \pm 40.1$ & $71.1 \pm 4.2$ \\
\hline
\end{tabular}

In experiments I and II, tubules were preincubated for $15 \mathrm{~min}$ followed by $30 \mathrm{~min}$ hypoxia and $60 \mathrm{~min}$ reoxygenation. Experimental agents were added either at the start or the end of hypoxia as indicated. In experiment III, tubules were preincubated for 30 min followed by 30 min hypoxia and $60 \mathrm{~min}$ reoxygenation. Experimental agents were present during the $30 \mathrm{~min}$ preincubation, then tubules were washed just before starting hypoxia. Values are means $\pm \mathrm{SE}$ of five to seven experiments for each manipulation. ${ }^{*} P<0.001,{ }^{\ddagger} P<0.01$, and ${ }^{\S} P<0.05$ vs. paired untreated posthypoxic tubules in experiments I and II. In experiment III, statistical comparisons were made between the washed untreated tubules and those treated with glycine or GSH. None of the differences were significant.

ine, a major product of rat tubule cell metabolism of glycine (25), was not protective. $N$-(2-mercaptopropionyl)-glycine, a thiol-containing derivative that has been reported to protect against ischemic tissue injury in vivo (26), had no beneficial effects. The thiol reagent, dithiothreitol (DTT), slightly improved only cell $\mathrm{K}^{+}$. There were no consistent beneficial effects of superoxide dismutase, catalase, deferoxamine, 1,10-phenanthroline, dimethylthiourea, or diphenyl-phenylenediamine.

Table IV. Effects of Various Agents on the Tubule Response to Hypoxia

\begin{tabular}{|c|c|c|c|c|c|}
\hline & \multicolumn{2}{|l|}{ Respiration } & \multirow[b]{2}{*}{ ATP } & \multirow[b]{2}{*}{$\mathrm{K}^{+}$} & \multirow[b]{2}{*}{ Protein recovery } \\
\hline & Basal & CCCLP & & & \\
\hline & \multicolumn{2}{|c|}{ natom eq oxygen/min per mg protein } & \multicolumn{2}{|c|}{ nmol/mg protein } & $\%$ \\
\hline Posthypoxic & $18.7 \pm 1.2$ & $44.0 \pm 4.0$ & $2.03 \pm 0.28$ & $196.3 \pm 10.5$ & $59.8 \pm 3.7$ \\
\hline Control & $53.9 \pm 2.4^{*}$ & $146.6 \pm 4.9^{*}$ & $8.68 \pm 0.40^{*}$ & $348.7 \pm 9.5^{*}$ & $96.6 \pm 2.4^{*}$ \\
\hline GSSG (2 mM) & $49.2 \pm 2.0^{\ddagger}$ & $83.3 \pm 6.0^{\S}$ & $6.21 \pm 0.56^{\ddagger}$ & $340.6 \pm 13.2^{\S}$ & $83.7 \pm 3.0^{\S}$ \\
\hline Serine ( $2 \mathrm{mM})$ & $18.6 \pm 1.4$ & $46.8 \pm 1.4$ & $2.90 \pm 0.31$ & $190.3 \pm 23.4$ & $63.6 \pm 7.9$ \\
\hline MPG (2 mM) & $15.7 \pm 1.9$ & $30.9 \pm 4.0$ & $1.62 \pm 0.38$ & $217.9 \pm 14.3$ & $46.8 \pm 6.5$ \\
\hline DTT (2 mM) & $22.6 \pm 2.9$ & $52.4 \pm 11.2$ & $2.79 \pm 0.76$ & $248.3 \pm 17.0^{*}$ & $50.3 \pm 6.1$ \\
\hline $\operatorname{SOD}(64 \mathrm{U} / \mathrm{ml})$ & $27.8 \pm 2.2$ & $58.9 \pm 2.4$ & $3.13 \pm 0.15$ & $212.1 \pm 8.8$ & $75.7 \pm 6.8^{\ddagger}$ \\
\hline Catalase $(100 \mu \mathrm{g} / \mathrm{ml})$ & $24.1 \pm 1.5$ & $52.3 \pm 4.5$ & $3.52 \pm 0.36$ & $215.4 \pm 11.7$ & $72.8 \pm 5.4$ \\
\hline Deferoxamine $(5 \mathrm{mM})$ & $23.4 \pm 1.3$ & $61.3 \pm 4.0$ & $3.65 \pm 0.21$ & $235.3 \pm 8.0$ & $68.3 \pm 6.4$ \\
\hline 1,10 -phenanthroline $(0.1 \mathrm{mM})$ & $25.5 \pm 0.7$ & $34.5 \pm 2.2$ & $4.86 \pm 0.73$ & $260.9 \pm 5.9$ & $72.1 \pm 3.7$ \\
\hline DMTU $(2 \mathrm{mM})$ & $15.0 \pm 2.5$ & $36.9 \pm 4.6$ & $2.11 \pm 0.36$ & $168.0 \pm 18.1$ & $65.0 \pm 7.5$ \\
\hline DPPD $(2 \mu \mathrm{M})$ & $24.3 \pm 3.4$ & $50.6 \pm 5.9$ & $2.26 \pm 0.58$ & $209.4 \pm 9.0$ & $75.6 \pm 6.8^{\S}$ \\
\hline
\end{tabular}

Tubules were treated with the indicated agent from the start of incubation at $37^{\circ} \mathrm{C}$. Metabolic parameters were measured after 30 min of hypoxia and 60 min reoxygenation. MPG, $N$-(2-mercaptopropionyl)-glycine; SOD, superoxide dismutase; DMTU, dimethylthiourea; DPPD, diphenyl-phenylenediamine. DMTU, DPPD, and 1,10-phenanthroline were from Aldrich Chemical Co. Deferoxamine mesylate was from CIBA, Summit, NJ. Values are means \pm SE for five to seven experiments with each agent. ${ }^{*} P<0.001,{ }^{\ddagger} P<0.01$, and ${ }^{\S} P<0.05$ vs. the paired, untreated, posthypoxic tubules for that group. This paired analysis accounts for the observation that cell ATP levels and protein recovery in the SOD, catalase, deferoxamine, and 1,10-phenanthroline groups, although larger than the average posthypoxic values for all groups studied, are not indicated as being significantly different. 


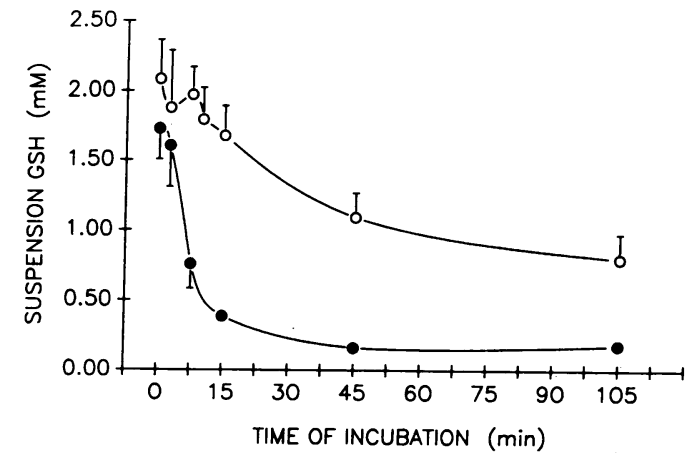

Figure 3. Tubule suspension GSH levels after addition of $2.0 \mathrm{mM}$ exogenous GSH. Total suspension GSH was measured in oxygenated tubules during $105 \mathrm{~min}$ of incubation at either $4^{\circ} \mathrm{C}\left(-\mathrm{O}_{-}\right)$or $37^{\circ} \mathrm{C}(-\bullet-)$. Values are means \pm SE for three experiments. Absent standard error bars were smaller than symbols for those points.

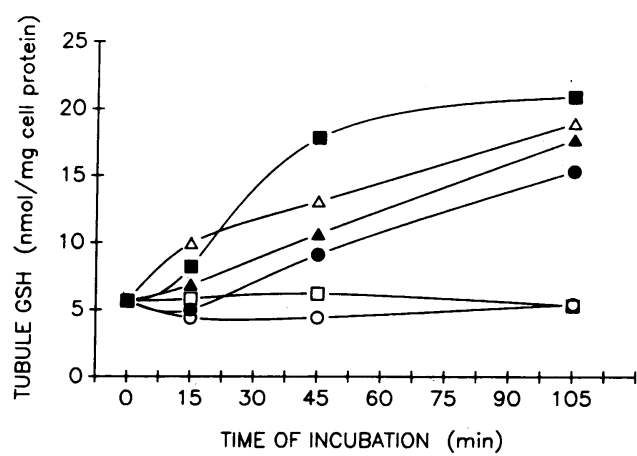

Figure 4. Tubule cell GSH levels after treatment with exogenous GSH or its component amino acids. Tubules were incubated for 105 min at $37^{\circ} \mathrm{C}$ under oxygenated conditions. Additions were present throughout the incubation period. $0.25 \mathrm{GSH}, 0.25 \mathrm{mM} \mathrm{GSH}$; other labels are as in Fig. 1. Values are means \pm SE for three to four experiments. Standard error bars were omitted for clarity. They were all $<10 \%$ of the means. (-o $\rightarrow$ ) Control; (-๑-) $0.25 \mathrm{GSH}$;

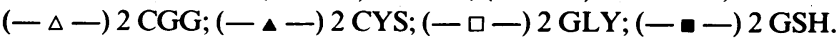

metabolic parameters $(3,4)$. In control tubule preparations the cells remain as part of tubule fragments, making it difficult to count them individually. Furthermore, during severe injury, progression to total cell disruption is common. For these reasons we have routinely emphasized metabolic rather than morphologic and vital dye studies to quantify cell injury. These measurements can also provide information on some of the major pathogenetic processes in the development of injury.

The normal tubule incubation conditions and the metabolic substrates provided, glucose, lactate, alanine, and butyrate, optimally support respiration only by intact cells so that the respiratory rates measured after hypoxia reflect the activity of these cells (3). The respiratory rates are reduced to the extent that disrupted cells contribute to the protein content of the suspension, but not to respiratory activity, and also as a result of whatever damage has occurred to mitochondria within cells that remain intact. Suspension ATP levels also represent mainly the contribution of intact cells since any ATP generated by mitochondria from highly permeabilized or completely disrupted cells would be rapidly hydrolyzed, much like exogenous ATP added to the incubation medium (4). As a result, the decreases of ATP measured after hypoxia reflect both the fact that disrupted cells contribute to the protein content but not to the ATP levels of the total suspension and any persisting abnormalities of ATP production or utilization in the surviving intact cells.

In prior studies with the tubule preparation, protein recovery after centrifugation through bromododecane appeared to provide a direct measure of the number of lethally injured cells since these cells separated from their tubule fragments and either disintegrated or did not pass through the bromododecane $(3,4)$. The reductions in protein recovery were similar in degree to the decrements of cell respiration and ATP levels, thus supporting the notion that these values were derived almost entirely from the remaining intact cells and also suggesting that they had recovered to near control levels in those cells $(3,4)$. Centrifugation through dibutylphthalate has been similarly utilized to quantify injury to isolated hepatocytes (27). In the present study, the decreases of cell respiratory rates and ATP levels seen after hypoxia were slightly less severe than
Tubules were treated with glycine or GSH from the beginning of incubation at $37^{\circ} \mathrm{C}$. Values are means $\pm \mathrm{SE}$ for assays on supernatants from three to five tubule preparations sampled at the indicated times. 
those reported previously; however, the decreases of protein recovery were much less extreme than in the prior studies (3, 4) and were not proportionate to the decreases of respiration and ATP levels. Observation of the fresh tubule suspensions stained with trypan blue revealed a substantial number of tubule fragments that retained their structural integrity but consisted mainly of trypan blue positive cells. These could also be found in the pellets obtained after centrifugation through bromododecane, indicating that protein recovery after the centrifugation procedure in the present study underestimated the extent of lethal cell injury. It is unclear whether the greater resistance of both tubule fragments and individual tubule cells to disruption after hypoxia is due to the slightly milder effect of hypoxia in this study or to differences in mechanical factors or collagenase relative to earlier studies. However, the respiratory rates and ATP levels now appear to be better indices of the extent of injury than protein recovery, although the latter parameter is still useful for comparing the effects of various maneuvers.

The extensive metabolism of GSH and its component amino acids by renal proximal tubules has been most completely characterized in the rat. A thiol oxidase in the basolateral membrane can convert GSH to the oxidized form, GSSG (28). Both GSH and GSSG are rapidly degraded to cysteinylglycine plus $\gamma$-glutamyl-amino acid compounds or free glutamate by brush border $\gamma$-glutamyl transpeptidase (11-13, 28, 29). Cysteinylglycine is hydrolyzed by a dipeptidase to cysteine and glycine that are readily transported into renal tubule cells (11-13). Cystine is also transported by tubule cells and converted intracellularly to cysteine (12). Within the tubule cell cysteinylglycine can be resynthesized by cysteinylglycine synthetase and then converted to GSH by GSH synthetase (12, 30). GSH, in turn, inhibits cysteinylglycine synthetase (12). Substantial amounts of intracellular GSH are secreted from tubule cells and, thus, become available for metabolism by the surface enzymes (12). Although extracellular cystine, cysteine, glycine, and glutamate all served as precursors for intracellular GSH synthesis by rat tubule cells, cystine or cysteine was required for increases of cell GSH, and cysteine was effective only when its concentration was $<1.0 \mathrm{mM}(30)$. Basolateral uptake of intact GSH has also been described $(13,31)$, but its significance relative to the large fluxes of the component amino acids in regulating cell GSH levels remains under investigation.

Whether all the mechanisms that have been delineated for rat tubules are applicable to the rabbit is not known; however, the studies in this paper suggest that differences are present. Degradation of GSH by the rabbit tubules was rapid, as reported for the rat (11). Cell GSH levels were substantially increased in oxygenated rabbit tubules by exogenous GSH, CGG, or cysteine alone but not by glycine alone. The ability of cysteine at a concentration of $2.0 \mathrm{mM}$ to raise cell GSH contrasts with the data reported for rat tubules where only concentrations $<1.0 \mathrm{mM}$ were effective for that purpose (30).

It is clear from much work with a variety of cell types that GSH plays a central role in protecting cells from injury by reactive oxygen metabolites and other activated, toxic compounds through actions to maintain protein sulfhydryl groups in the reduced state, to limit lipid peroxidation, and to directly combine with the toxic reactive metabolites (6-8). Provision of extracellular GSH has been shown to reduce the toxicity of tert-butyl hydroperoxide and menadione to isolated intestinal cells (32), of paraquat to isolated pulmonary epithelial cells (33), and of cadmium to isolated hepatocytes (34). The effects on the intestinal cells and pulmonary epithelial cells did not require GSH catabolism and appeared to involve uptake of intact GSH $(32,33)$.

Much recent interest has focused on roles for reactive oxygen metabolites and alterations of cellular GSH metabolism in the pathogenesis of oxygen deprivation-induced tissue injury in a number of organs, including the kidney. GSH infusions protected the liver (9) and kidney (10) from oxygen deprivation-induced injury. Renal ischemia results in reductions of tissue GSH (35) and production during reperfusion of reactive oxygen metabolites as indicated by increases of the lipid peroxidation product, malondialdehyde (36). Ischemic acute renal failure was ameliorated by agents that reduce the availability of reactive oxygen metabolites, including superoxide dismutase, allopurinol, and dimethylthiourea (36).

The present study has indeed documented a major, direct protective effect of GSH on the response of rabbit renal proximal tubules to hypoxia, but the data indicate that this protection is unrelated to cell GSH or reactive oxygen metabolites. Instead, it appears to be mediated by glycine produced from GSH metabolism. Glycine protected as well as GSH throughout the concentration range tested and the protection provided by both agents occurred during hypoxia and required their presence in the medium then. Of additional importance relative to a role for glycine under physiological conditions in vivo is the fact that the $0.25 \mathrm{mM}$ concentration required for some protection to be evident is in the range of normal plasma glycine levels, $0.20-0.30 \mathrm{mM}(13,17)$. Plasma GSH approximates $0.025 \mathrm{mM}$ (13).

In contrast to the results with glycine, little evidence of a role for extracellular or intracellular GSH or reactive oxygen metabolites was obtained. Like GSH, GSSG also protected. Neither of the thiol reagents tested, $N$-(2-mercaptopropionyl)glycine or DTT, was protective. Cysteine, which increased intracellular GSH levels nearly as much as exogenous GSH, did not protect the tubules. Furthermore, agents that ameliorate reactive oxygen-metabolite-induced injury in a variety of models (7), including superoxide dismutase, catalase, deferoxamine, 1,10-phenanthroline, diphenylphenylenediamine, and dimethylthiourea, were not consistently protective. We have previously shown that allopurinol is also without effect in the rabbit tubule preparation (4).

Prior studies have indicated that amino acid mixtures may modify the response of the kidney to ischemic acute renal failure; however, both beneficial and deleterious effects have been reported $(14,15)$ reflecting the heterogeneous properties of individual amino acids, including the potential for direct tubule cell toxicity $(16,18)$. Function of isolated perfused rat kidneys spontaneously deteriorates due to hypoxic damage to the medullary thick ascending limb $(17,37)$. This damage was prevented by including cysteine, glycine, and glutamate in the perfusion medium (17). Although the amino acids increased tissue GSH levels, the protection could be dissociated from changes in tissue GSH (37). The glycine concentration used in these latter studies, $2.3 \mathrm{mM}$, was in the range that we have found to be highly protective. That glycine would have been protective for the isolated perfused kidney if administered without other amino acids is suggested by the observation, during studies of metabolism of $5 \mathrm{mM}$ glycine by the isolated perfused kidney, that no functional deterioration occurred 
during prolonged perfusion (25). These data make it likely that the protective effects of glycine will be evident in further studies of the intact kidney and that this protection will not be limited to the proximal tubule or the rabbit.

The results of the present study localize the cytoprotective action of glycine to the period of oxygen deprivation. ATP levels of the glycine-treated tubules were slightly but signifcantly higher at the end of oxygen deprivation than in the untreated tubules. It is unlikely, however, that glycine was simply acting as a metabolic substrate or that its effects were related only to better preservation of ATP levels because ample substrates, including glucose were available in the incubation medium throughout all phases of the protocol. Also, glycine is a relatively poor substrate for energy production in the kidney (38), and the protective effects of exogenous GSH occurred in spite of the fact that it did not maintain the slightly higher ATP levels seen with glycine alone.

Both brush border and basolateral membrane uptake mechanisms have been identified for glycine $(39,40)$ and it is extensively metabolized by the kidney. Metabolic processes involving glycine include: (a) Incorporation into GSH as detailed above. $(b)$ The glycine cleavage reaction in which glycine serves as a methyl donor to tetrahydrofolate to form $N^{5}, N^{10}$ methylene-tetrahydrofolate with the production of ammonia $(41,42)$. (c) $N^{5}, N^{10}$-methylene-tetrahydrofolate can serve as a methyl donor to glycine itself to form serine in a reaction catalyzed by serine hydroxymethyltransferase (25). Glycine markedly stimulated serine production by rat tubules (25). It did not have a substantial effect on serine production by the rabbit tubules. $(d)$ Oxidative deamination of glycine by glycine oxidase can convert it to glyoxylate. No evidence for this pathway was found in rat kidney slices (42). (e) Involvement in the first step of creatine synthesis in which arginine and glycine are converted to guanidoacetic acid and ornithine (43). $(f)$ Incorporation during de novo synthesis of purines and heme $(44,45)$. $(g)$ Participation in conjugation reactions with carboxylic acids (46-48). Glycine $N$-acyltransferase, which mediates production of acylglycine from acyl-coenzyme A (CoA) and glycine, has been identified in both kidney and liver $(47,48)$.

The glycine $N$-acyltransferase reaction is of particular interest with regard to glycine's protective effects during oxygen deprivation because it provides a mechanism whereby glycine could participate in the detoxification of acyl-CoA compounds generated from fatty acids during oxygen deprivation. Inhibition of $\beta$-oxidation during oxygen deprivation leads to accumulation of these amphipathic molecules that have a significant potential to disrupt membrane structure and function because of their detergent properties (49-52). Most study of their role in oxygen deprivation-induced injury has been in myocardial ischemia. There, the increases of acyl-CoA occur predominantly in the mitochondria and are associated with inhibition of the mitochondrial adenine nucleotide translocase (53). Proximal tubules use fatty acids as a main energy source $(54,55)$. In the isolated tubule preparation, butyrate serves as a short chain fatty acid that is highly effective for this purpose (55). Thus, ample substrate for accumulation of acyl-CoA is present in the experimental system.

The feasibility of this mechanism for protection by glycine is suggested by its role in treatment of acyl-CoA dehydrogenase deficiencies (56) and in studies of hypoglycin. This toxic amino acid produced by the Jamaican ackee fruit is metabo- lized to methylene cyclopropyl-acetyl-CoA, an inhibitor of mitochondrial oxidation of short chain acyl-CoA compounds. The toxicity of hypoglycin can be markedly ameliorated by treatment with glycine which forms conjugates with both the methylene cyclopropyl-acetyl-CoA and the short chain acyl compounds that accumulate (57). Additional experiments will be required to determine whether a similar mechanism is, in fact, operative during oxygen-deprivation injury to the isolated tubules.

In summary, both GSH and glycine provide substantial protection against hypoxic injury to isolated kidney tubules, and the major protective factor in both cases appears to be the glycine. Further studies of this process may provide insight into basic mechanisms of oxygen deprivation-induced cell injury as well as into a novel cytoprotective agent with practical applications.

\section{Acknowledgments}

We are grateful to Dr. George Tarr, Department of Biological Chemistry, University of Michigan for his assistance with the amino acid assays and to Natalka Baczynskyj for her excellent work on several aspects of these studies.

These studies were supported by National Institutes of Health (NIH) grant DK-34275 and by the Veterans Administration. Dr. Weinberg is the recipient of NIH Research Career Development Award DK-01337.

\section{References}

1. Trump, B. F., and I. K. Berezesky. 1985. The role of calcium in cell injury and repair: a hypothesis. Surv. Synth. Pathol. Res. 4:248256.

2. Jennings, R. B., and C. Steenbergen. 1985. Nucleotide metabolism and cellular damage in myocardial ischemia. Annu. Rev. Physiol. 47:727-749.

3. Weinberg, J. M. 1985. Oxygen deprivation-induced injury to isolated rabbit kidney tubules. J. Clin. Invest. 76:1193-1208.

4. Weinberg, J. M., and H. D. Humes. 1986. Increases of cell ATP produced by exogenous adenine nucleotides in isolated rabbit tubules. Am. J. Physiol. 250:F720-F733.

5. Takano, T., S. P. Soltoff, S. Murdaugh, and L. J. Mandel. 1985. Intracellular respiratory dysfunction and cell injury in short-term anoxia of rabbit renal proximal tubules. J. Clin. Invest. 76:2377-2384.

6. Bellomo, G., and S. Orrenius. 1985. Altered thiol and calcium homeostasis in oxidative hepatocellular injury. Hepatology (Baltimore). 5:876-882.

7. Weinberg, J. M. 1987. The cellular basis of nephrotoxicity. In Disease of the Kidney. R. W. Schrier and C. W. Gottschalk, editors. Little, Brown and Co., Boston. 1137-1 196.

8. Starke, P. E., and J. L. Farber. 1985. Endogenous defenses against the cytotoxicity of hydrogen peroxide in cultured rat hepatocytes. J. Biol. Chem. 260:86-92.

9. Jennische, E. 1984. Possible influence of glutathione on postischemic liver injury. Acta Pathol. Microbiol. Immunol. Scand. 92:55-64.

10. Paller, M. S. 1986. Hypothyroidism protects against free radical damage in ischemic acute renal failure. Kidney Int. 29:1 162-1166.

11. Jones, D. P., P. Moldeus, A. H. Stead, K. Ormstad, H. Jornvall, and S. Orrenius. 1979. Metabolism of glutathione and a glutathione conjugate by isolated kidney cells. J. Biol. Chem. 254:2787-2792.

12. Meister, A., and M. E. Anderson. 1983. Glutathione. Annu. Rev. Biochem. 52:711-760.

13. Abbott, W. A., R. J. Bridges and A. Meister. 1984. Extracellular metabolism of glutathione accounts for its disappearance from the basolateral circulation of the kidney. J. Biol. Chem. 259:15393-15400.

14. Toback, F. G., D. E. Teegarden, and L. J. Havener. 1979. Amino acid mediated stimulation of renal phospholipid biosynthesis after acute tubular necrosis. Kidney Int. 15:542-547. 
15. Zager, R. A., and M. A. Venkatachalam. 1983. Potentiation of ischemic renal injury by amino acid infusion. Kidney Int. 24:620-625.

16. Zager, R. A., G. Johannes, S. E. Tuttle, and H. M. Sharma. 1983. Acute amino acid nephrotoxicity. J. Lab. Clin. Med. 101:130 140.

17. Epstein, F. D., J. T. Brosnan, J. D. Tange, and B. D. Ross. 1982. Improved function with amino acids in the isolated perfused kidney. Am. J. Physiol. 243:F284-F292.

18. Racusen, L. C., A. Whelton, and K. Solez. 1985. Effects of lysine and other amino acids on kidney structure and function in the rat. Am. J. Pathol. 120:436-442.

19. Weinberg, J. M., P. G. Harding, and H. D. Humes. 1983. Alterations in renal cortical cation homeostasis during mercuric chloride and gentamicin nephrotoxicity. Exp. Mol. Pathol. 39:43-60.

20. Tarr, G. E. 1986. Manual Edman sequencing systems. In Methods of Protein Microcharacterization. J. E. Shively, editor. Humana Press, Inc., Clifton, NJ. 155-194.

21. Hissin, P. J. and R. Hilf. 1976. A fluorometric method for determination of oxidized and reduced glutathione in tissues. Anal. Biochem. 74:214-226.

22. Lowry, O. H., N. J. Rosebrough, A. L. Farr, and R. J. Randall. 1951. Protein measurement with the Folin phenol reagent. J. Biol. Chem. 193:265-275.

23. Dixon, W. J. 1983. BMDP Statistical Software. University of California at Berkely, Berkely, CA. 359-387.

24. Snedecor, G. W., and W. G. Cochran. 1980. Statistical methods. 7th edition. Iowa State University Press, Ames, IA. 233-237.

25. Lowry, M., D. E. Hall, and J. T. Brosnan. 1986. Serine synthesis in rat kidney: studies with perfused kidney and cortical tubules. $\mathrm{Am}$. J. Physiol. 250:F649-F658.

26. Mitsos, S. E., T. E. Askew, J. C. Fantone, S. L. Kunkel, G. D. Abrams, A. Schork, and B. R. Lucchesi. 1986. Protective effects of N-2-mercaptopropionyl glycine against myocardial reperfusion injury after neutrophil depletion in the dog: evidence for the role of intracellular-derived free radicals. Circulation. 73:1077-1086.

27. Fariss, M. W., M. K. Brown, J. A. Schmitz, and D. J. Reed. 1985. Mechanism of chemical-induced toxicity. I. Use of a rapid centrifugation technique for the separation of viable and nonviable hepatocytes. Toxicol. Appl. Pharmacol. 79:283-295.

28. Lash, L. H., D. P. Jones, and S. Orrenius. 1984. The renal thiol (glutathione) oxidase. Subcellular localization and properties. Biochim. Biophys. Acta. 779:191-200.

29. Welbourne, T. C., and P. D. Dass. 1982. Function of renal gamma-glutamyltransferase: significance of glutathione and glutamine interaction. Life Sci. 30:793-801.

30. Ormstad, K., D. P. Jones, and S. Orrenius. 1980. Characteristics of glutathione biosynthesis by freshly isolated rat kidney cells. $J$. Biol. Chem. 255:175-181.

31. Lash, L. H., and D. P. Jones. 1984. Renal glutathione transport. Characteristics of the sodium-dependent system in the basal-lateral membrane. J. Biol. Chem. 23:14508-14514.

32. Lash, L. H., T. M. Hagen, and D. P. Jones. 1986. Exogenous glutathione protects intestinal epithelial cells from oxidative injury. Proc. Natl. Acad. Sci. USA. 83:4641-4645.

33. Hagen, T. M., L. A. Brown, and D. P. Jones. 1986. Protection against paraquat-induced injury by exogenous GSH in pulmonary alveolar type II cells. Biochem. Pharmacol. 35:4357-4542.

34. Stacey, N. H. 1986. The amelioration of cadmium-induced injury in isolated hepatocytes by reduced glutathione. Toxicology. 42:85-93.

35. McCoy, R. N., M. A. Ayon, K. E. Hill, J. H. Stein, and R. F. Burk. 1986. Oxidant stress following renal ischemia. Kidney Int. 29:306. (Abstr.)

36. Paller, M. S., J. R. Hoidal, and T. F. Ferris. 1984. Oxygen free radicals in ischemic acute renal failure in the rat. J. Clin. Invest. 74:1156-1164.

37. Brezis, M., S. Rosen, P. Silva, and F. H. Epstein. 1983. Selective glutathione depletion on function and structure of the isolated perfused rat kidney. Kidney Int. 24:178-184.

38. Cohen, J. J., and A. J. Black. 1982. Substrate-selective maintenance of tissue $\mathrm{K}^{+}$in perfused rat kidney. Am. J. Physiol. 242:F360F369.

39. Barfuss, D. W., J. M. Mays, and J. A. Schafer. 1980. Peritubular uptake and transepithelial transport of glycine in isolated proximal tubules. Am. J. Physiol. 238:F324-F333.

40. Schwab, S. J., and M. R. Hammerman. 1985. $\mathrm{Na}^{+}$gradient-dependent glycine uptake in basolateral membrane vesicles from the dog kidney. Am. J. Physiol. 249:F338-F345.

41. Kikuchi, G. 1973. The glycine cleavage system: composition, reaction mechanism, and physiological significance. Mol. Cell. Biochem. 1:169-187.

42. Rowsell, D. V., and M. M. Al-Naama. 1982. Glycine metabolism in rat kidney cortex slices. Biochem. J. 204:313-321.

43. McGuire, D. M., M. D. Gross, R. P. Elde, and J. F. Van Pilsum. 1986. Localization of L-arginine-glycine amidinotransferase protein in rat tissues by immunofluorescence microscopy. J. Histochem. Cytochem. 34:429-435.

44. Seegmiller, J. E. 1975. Purine metabolism. Arthritis. Rheum. 18:681-686.

45. Granick, S., and S. I. Beale. 1978. Heme, chlorophyll and related compounds: biosynthesis and metabolic regulation. Adv. Enzymol. 46:33-203.

46. Prescott, L. F. 1984. Drug conjugation in clinical toxicology. Biochem. Soc. Trans. 12:96-99.

47. Schachter, D., J. G. Manis, and J. V. Taggart. 1954. Renal synthesis, degradation and active transport of aliphatic acyl amino acids. Relationship to p-aminohippurate transport. J. Biol. Chem. 208:537-544.

48. James, M. O., and J. R. Bend. 1978. Perinatal development of, and effect of chemical pretreatment on, glycine $\mathrm{N}$-acyltransferase activities in liver and kidney of rabbit and rat. Biochem. J. 172:293-299.

49. Shug, A. L., J. H. Thompson, J. D. Folts, N. Bittar, M. I. Klein, J. R. Koke, and P. J. Huth. 1978. Changes in tissue levels of carnitine and other metabolites during myocardial ischemia and anoxia. Arch. Biochem. Biophys. 187:25-33.

50. Idell-Wenger, J. A., L. W. Grotyohann, and J. R. Neely. 1978. Coenzyme A and carnitine distribution in normal and ischemic hearts. J. Biol. Chem. 253:4310-4318.

51. Katz, A. M., and F. C. Messineo. 1981. Lipid-membrane interactions and the pathogenesis of ischemic damage in the myocardium. Circ. Res. 48:1-16.

52. Matthys, E., Y. Patel, J. Kreisberg, J. H. Stewart, and M. A. Venkatchalam. 1984. Lipid alterations induced by renal ischemia: pathogenetic factor in membrane damage. Kidney Int. 26:153-161.

53. Shug, A. L., E. Shrago, N. Bittar, J. D. Folts, and J. R. Koke. 1975. Acyl-CoA inhibition of adenine nucleotide translocation in ischemic myocardium. Am. J. Physiol. 228:689-692.

54. Guder, W. G., S. Wagner, and G. Wirthensohn. 1986. Metabolic fuels along the nephron: pathways and intracellular mechanisms of interactions. Kidney Int. 29:41-45.

55. Weidemann, M. J., and H. A. Krebs. 1969. The fuel of respiration of rat kidney cortex. Biochem. J. 112:149-166.

56. Cohn, R. M., M. Yudkoff, R. Rothman, and S. Segal. 1978. Isovaleric acidemia: use of glycine therapy in neonates. $N$. Engl. $J$. Med. 299:996-999.

57. Al-Bassam, S. S., and H. S. A. Sherratt. 1981. The antagonism of the toxicity of hypoglycin by glycine. Biochem. Pharmacol. 30:2817-2824. 